\title{
Model of Three-Limb Three-Phase Transformer Based on Nonlinear Open Circuit Characteristic with Experimental Verification
}

\author{
Mitar Simić, Tomislav B. Šekara, and Srđan Jokić
}

\begin{abstract}
This paper describes the realization of a threephase transformer model based on a non-linear open-circuit characteristic. The proposed model is based on the fact that in case of a star connection with a neutral wire on the primary windings for all three phases, the applied voltage presents phase voltage and line (phase) currents are magnetization currents. These variables are available for measuring and it is easy to obtain three non-linear open circuit characteristics. The results of simulations and a comparison with references and experimental results verified this approach.
\end{abstract}

Keywords - harmonic analysis, nonlinear open-circuit characteristic, transformers.

\section{INTRODUCTION}

$T_{1}$ $\mathrm{HE}$ modeling in engineering is considered as very important because with models researchers are able to investigate and find dependences which exist on a real object in a safe and simple manner. The importance of modeling in electrical engineering can be explained as the capability to simulate extreme work conditions without danger, have access to variables which are not easy or cannot be measured on real objects, simplicity and safety. The importance of own built models is full access to and manipulation with mathematical equations on which a model is based.

The modeling of electrical transformer has represented a very interesting research topic for a long period of time. As a result, different approaches in modeling have been developed.

The first idea is to develop a mathematical model based on an equivalent electrical circuit [1]-[3]. Linear parameters as winding inductance and resistance can be

Paper received February 19, 2014; revised May 27, 2014; accepted June 7, 2014. Date of publication July 31, 2014. The associate editor coordinating the review of this manuscript and approving it for publication was Prof. Vladimir Petrović.

This paper is a revised and expanded version of the paper presented at the 21th Telecommunications Forum TELFOR 2013.

Authors are grateful to the company KV Team Sarajevo for financial support to research.

Mitar Simić is with the NORTH Point Ltd, Subotica, Serbia (e-mail: mitarsimic@yahoo.com).

Tomislav B. Šekara is with the Faculty of Electrical Engineering, University of Belgrade, Serbia (e-mail: tomi@etf.rs).

Srđan Jokić is with the Faculty of Electrical Engineering, University of East Sarajevo, Bosnia and Herzegovina (e-mail: srdjan.jokic@etf.unssa.rs.ba). easily determined through open and short-circuit tests. Nonlinear behavior of magnetic core is usually included by using either nonlinear curves flux-current, controlled current sources or nonlinear inductance which requires a complex mathematical model.

For some applications a detailed harmonic analysis and behavior in transient are necessary which requires the inclusion of mutual parasitic capacitances between windings and between windings and case. More details can be found in [4]-[9].

For a more precise description of core nonlinearity, magnetic hysteresis must be included [10], [11]. However, sometimes the width of hysteresis curve is tight enough so that the results obtained with the usage of nonlinearity based on the curve of the first magnetization are acceptable.

In [12] authors deal with MSC/EMAS simulation of a three-phase power transformer using a 3D finite element model. The most important part of presented simulation is the modeling of multiturn windings and the iron core by means of anisotropic material properties.

A very frequent approach in transformer modeling is the implementation of magnetic reluctances [10], [13]-[16].

Some authors describe the connections between variables inside the transformer by mutual inductances, but, for a precise analysis these inductances must be nonlinear with a need for complex mathematical calculations for parameter estimation [17]-[19].

The main purpose of this paper is to investigate quotations from literature about magnetization curves and the behavior of transformers in specific work conditions and to propose a model of a three-phase transformer with a simple procedure for parameter estimation and accurate results in a wide range of work conditions.

\section{THEORY OF THREE PHASE TRANSFORMERS}

A three-phase transformer can be realized by properly connecting three single-phase transformers or designed as a single unit as shown in Fig. 1. The realization with three single phase type requires more materials and is more expensive, whereas the single unit three-phase transformer requires less materials and is cheaper. When a winding fault occurs in one unit of the three single phase type then only that particular unit is replaced by a similar unit, but a winding fault in three phase single unit type requires replacement of the complete transformer. The three singlephase type of transformer requires more space. 
The construction presented in Fig. 1 is very common in Europe [20]. The transformer has three limbs. Each phase winding is wound around one of the limbs. Each limb has two windings: primary and secondary. On each limb, the low voltage winding is placed nearer to the steel core and the high voltage winding is placed over the low voltage winding. Insulation is placed between the low voltage and high voltage windings. Also, the low voltage winding is insulated from the core. The reason for placing the low voltage winding nearer to the core is the requirement for less insulation.

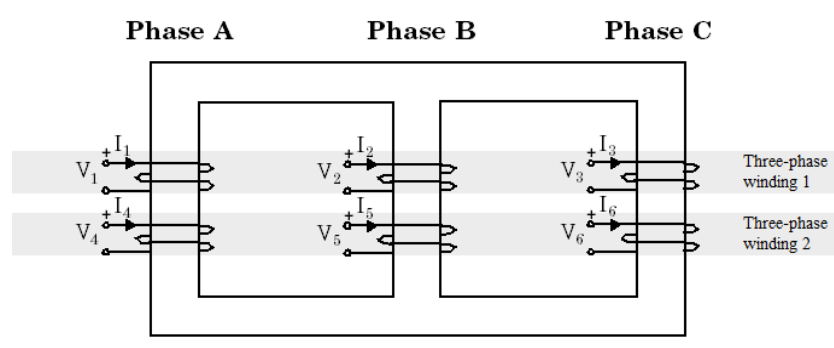

Fig. 1. Three-phase transformer with three limbs.

To reduce eddy current losses, the core of a transformer is made of thin sheets of silicon steel stacked together. The sheets of silicon steels are insulated from each other. The core assembly is put inside the steel tank filled with oil. The oil of the transformer acts as an insulator between the winding coils and a steel tank. The oil of the transformer also helps in cooling the transformer. The transformer oil also dampens the noise originating from the core assembly.

It can be seen in Fig. 1 that, in comparison with other two phases (A and $\mathrm{C}$ ), the magnetic resistance of phase in the middle (phase B) is the smallest, so magnetization current and open-circuit current as well of this phase will be the smallest. This means that the three-phase system of open-circuit currents will be unsymmetrical.

\section{MAGNETIZATION CURRENTS OF THREE PHASE TRANSFORMERS}

The primary and secondary windings of three-phase transformer can be connected in three different ways: a star (Y), delta (D) and "zigzag" (Z) connection [20]. The most common connections in practice are star-star (Yy), delta-star (Dy) or vice versa and star-zigzag (Yz).

Based on considerations about the magnetization current of single-phase transformer and taking into account odd harmonics (especially the third), the magnetization currents of three-phase transformer can be analyzed. It is very important to remember that, for a three-phase transformer, magnetization currents are dependent on windings connection, so magnetization currents for starstar and delta-star connections have to be analyzed separately. In case of a star-star connection it is necessary to analyze two cases: a primary winding with and without a neutral wire [20].

\section{MODEL OF THREE-LIMB THREE-PHASE TRANSFORMER AND OBTAINED RESULTS}

The proposed model of a three-phase transformer is based on the results and conclusions obtained for a single- phase transformer [21] and [22], where also all important facts necessary for understanding the implementation of core nonlinearity can be found. The main idea is that the nonlinearity of the magnetic core of a three-phase transformer can be implemented with three separated nonlinear open-circuit characteristics.

This approach verified with single-phase transformers $[21,22]$ can be used with three-phase transformers, because in case of a star connection with a neutral wire on the primary windings for all three phases, the applied voltage presents phase voltage and line (phase) currents are magnetization currents. These variables are available for measuring and it is easy to obtain three nonlinear open circuit characteristics.

The structure of one phase of a nonlinear three-phase transformer model is presented in Fig. 2 and Fig. 3. The model consists of three identical parts with differences in magnetic core model parameters for each phase with mutual connections to implement the law of conservation of energy and to ensure the simulation of all most common connections without a need to change anything in the model.

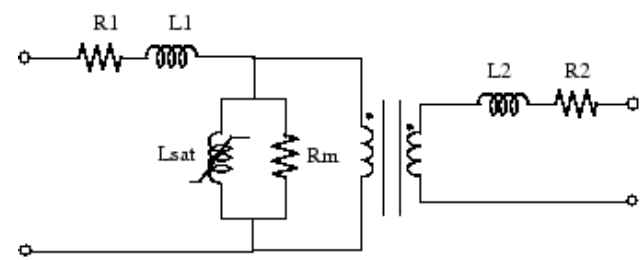

Fig. 2. Structure of one phase of three-phase transformer nonlinear model.
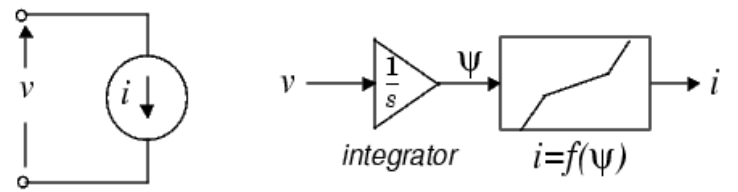

Fig. 3. Structure of nonlinear model of magnetic core block scheme.

Winding resistances $\left(\mathrm{R}_{1}=\mathrm{R}_{2}=11.14 \Omega\right)$ and leakage inductances $\left(\mathrm{L}_{1}=\mathrm{L}_{2}=4.9 \mathrm{mH}\right)$ are determined with standard open-circuit and short-circuit tests, as described in [21], [22].

The following procedure for obtaining nonlinear opencircuit characteristics should be used: primary voltage should be increased from $0 \mathrm{~V}$ to a nominal voltage, for example in steps of $10 \mathrm{~V}$, and the current in primary windings for each phase should be measured. By neglecting the resistance and inductance of winding, it can be assumed that in open-circuit condition, the current through a primary winding represents magnetization current with a value determined by the resistance and inductance of the magnetic core of transformer.

It is necessary that primary windings are connected in star with the neutral wire connected with the ground of power supply unit. With this configuration, a winding is connected directly to the phase voltage which is equivalent to the situation with a single-phase transformer. Based on theory presented in [20], it can be assumed that magnetization currents for phases $\mathrm{A}$ and $\mathrm{C}$ are equal and 
higher than the magnetization current of phase B as shown in the Fig. 4. But, laboratory tests performed on the Faculty of Electrical Engineering in Banja Luka presented in [22] show that there is a small deviation and that the magnetization currents of phases $\mathrm{A}$ and $\mathrm{C}$ are a little bit asymmetrical, as shown in Fig. 5. The details of investigated transformer are: $400 \mathrm{~V}, 10 \mathrm{kVA}$ [22]. Because of simplicity, in this paper the assumption that the magnetization currents of phases $\mathrm{A}$ and $\mathrm{C}$ are equal, as presented in Fig. 4, is used.

In the following text a comparison of experimental and the result obtained with the proposed three-phase transformer model is presented. The analyzed transformer has a magnetic core, as shown in Fig. 1, with a winding turns ratio of 1 with winding parameters described in the Appendix.

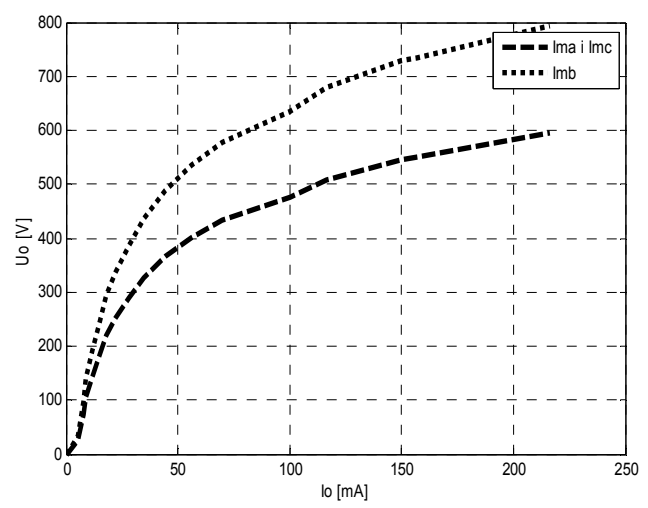

Fig. 4. Symmetrical open-circuit characteristics of threephase electrical transformer used in model.

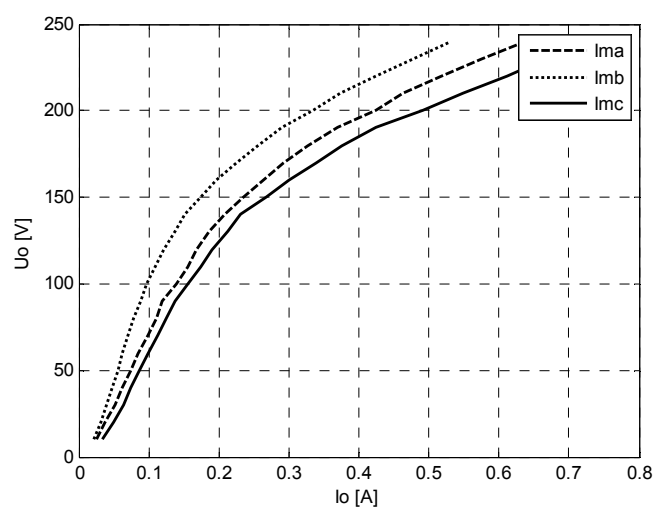

Fig. 5. Experimentally obtained open-circuit characteristics of three-phase electrical transformer.

\section{A. Primary windings connected in star without a neutral wire}

In this case, because there is no neutral wire, there cannot be a resultant current flowing through a neutral wire. It is presented in [20] that the sum of all higher harmonics which are delayed by one third of the period is equal to zero. However, this is not true for the third harmonic and all harmonics divisible by three. According to this, in primary windings connected in star without a neutral wire there cannot be current with a third harmonic. In Fig. 6 the waveforms of open-circuit currents obtained by the model are presented.

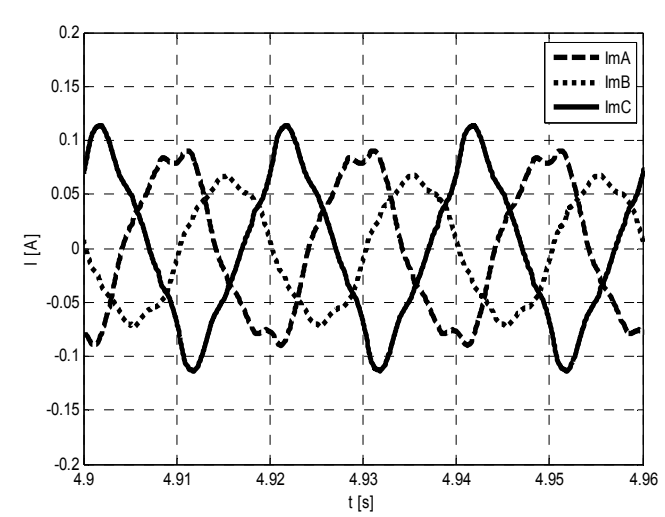

Fig. 6 Waveforms of open-circuit currents in connection star-star without neutral wire on the primary side - model

In Fig. 7 the waveforms of open-circuit currents obtained experimentally are presented. Blue line is phase $\mathrm{A}$, red line is phase $\mathrm{B}$ and green line is phase $\mathrm{C}$.

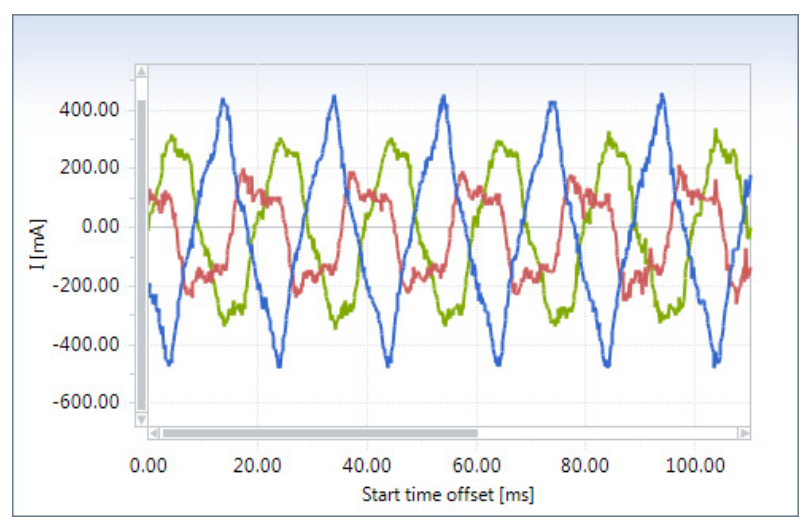

Fig. 7. Waveforms of open-circuit currents in connection star-star without neutral wire on the primary side experiment.

From these graphs it can be concluded that obtained waveforms are very similar. As an addition, in Fig. 8 the harmonic spectrum of magnetization current of phase $\mathrm{A}$ is presented. These results are obtained by the model, and from experimental results presented in Fig. 9 it can be realized there is very good agreement with experimental results. Similar results are obtained for the other two phases.

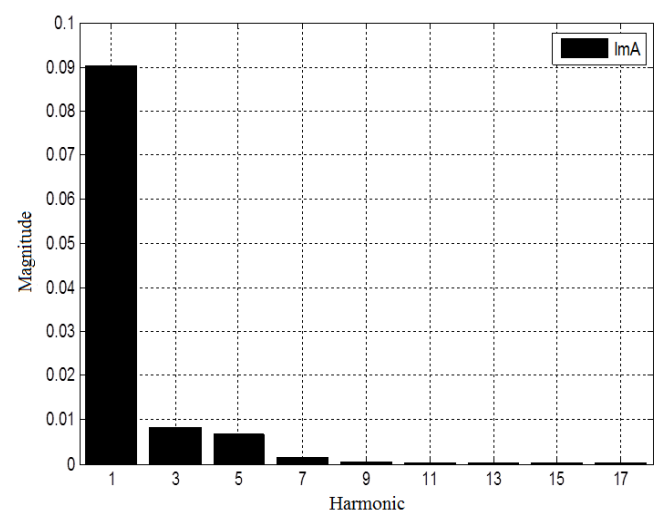

Fig. 8 Harmonic spectrum of open-circuit currents in connection star-star without neutral wire on the primary side - model 


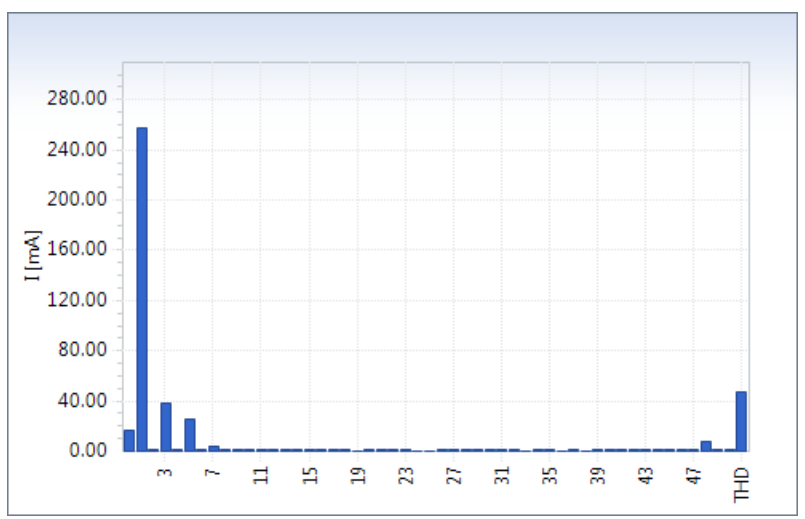

Fig. 9. Harmonic spectrum of open-circuit currents in connection star-star without neutral wire on the primary side - experiment.

\section{B. Primary windings connected in star with neutral wire}

Based on the theory, if the transformer with a magnetic circuit presented in Fig. 1 is used, the expected results of simulation will be [20]:

- The sum of phase currents is flowing through a neutral wire. The sum of basic harmonics of all three phases is equal to zero. This is also true for the fifth and the seventh harmonic. However, this is not true for the third harmonic. In fact, a triple value of the third harmonic current is flowing through a neutral wire. This is also true for all higher harmonics divisible by three.

- Because the magnetization current of phase B is smaller than the currents of phase $\mathrm{A}$ and $\mathrm{C}$, the resultant current which is flowing through a neutral wire is deformed. The frequency of that current is three times bigger than a base harmonic.

In Fig. 10 the waveforms of open-circuit currents obtained by the model are presented.

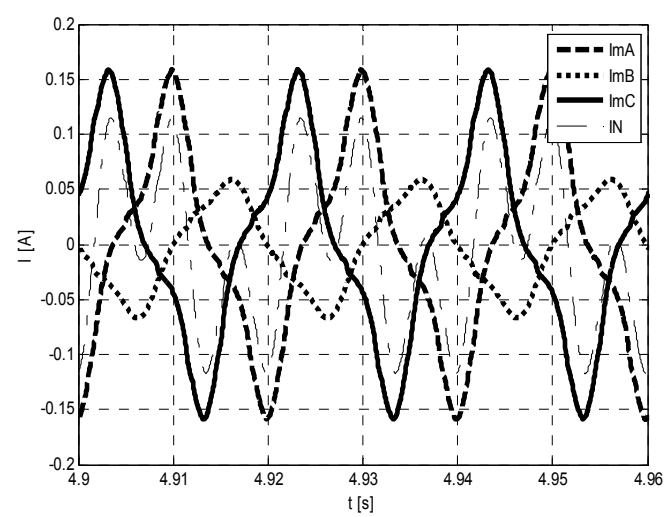

Fig. 10. Waveforms of open-circuit currents in connection star-star with neutral wire on the primary side - model.

In Fig. 11 the waveforms of open circuit currents obtained experimentally are presented.

As can be seen from Fig. 10, the frequency of neutral wire current is three times higher than the frequency of magnetization currents. This is confirmed by the results of harmonic analysis presented in Fig. 14.

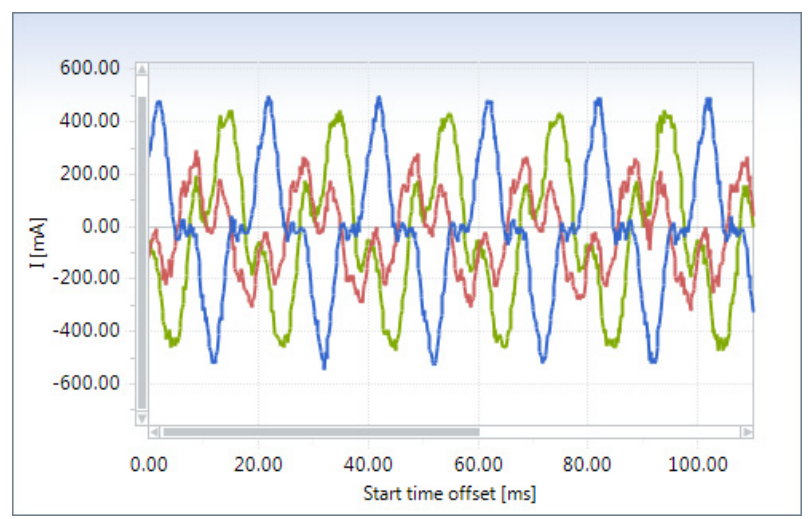

Fig. 11. Waveforms of open circuit currents in connection star-star with neutral wire on the primary side experiment.

Results obtained by the model are very similar to the theoretical analysis presented in [20] but there is a difference in comparison with experimental results. This difference is a consequence of different effective magnetic length of each phase, as noted before (Fig. 4 and Fig. 5).

In Fig. 12 the harmonic spectrum of phase A magnetization current is presented. These results are obtained by the model and it can be concluded from Fig. 13 that there is a very good agreement with experimental results. Similar results are obtained for the other two phases.

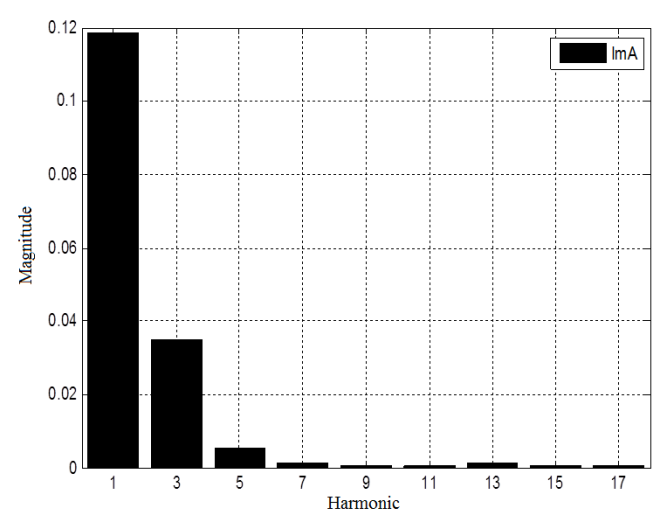

Fig. 12. Harmonic spectrum of open-circuit currents in connection star-star with neutral wire on the primary side - model.

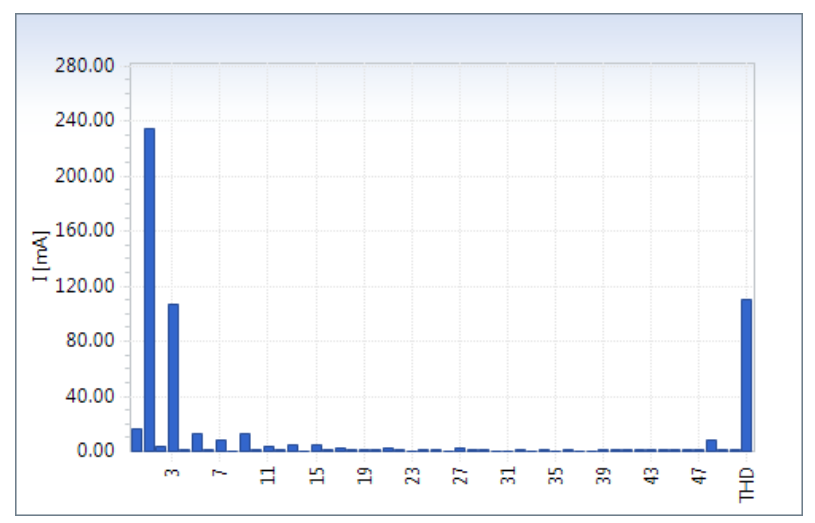

Fig. 13. Harmonic spectrum of open-circuit currents in connection star-star with neutral wire on the primary side - experiment. 


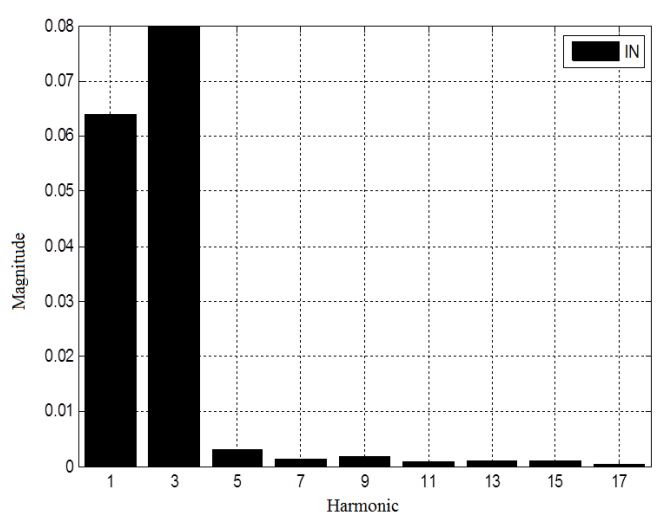

Fig. 14. Harmonic spectrum of neutral wire current in open-circuit test - model.

\section{Primary windings connected in delta}

When primary windings have a delta connection every winding is connected directly to the phase (at the same time that is a line voltage) so in line currents there are no third harmonics. Because the third harmonics of phase currents are equal at the same moment that results in that delta is a short circuit for the third and all higher harmonics divisible by three. For this connection experimental results were not accessible and discussion is made in comparison with theoretical facts presented in the literature [20].

In Fig. 15 the waveforms of open circuit currents obtained by the model are presented.

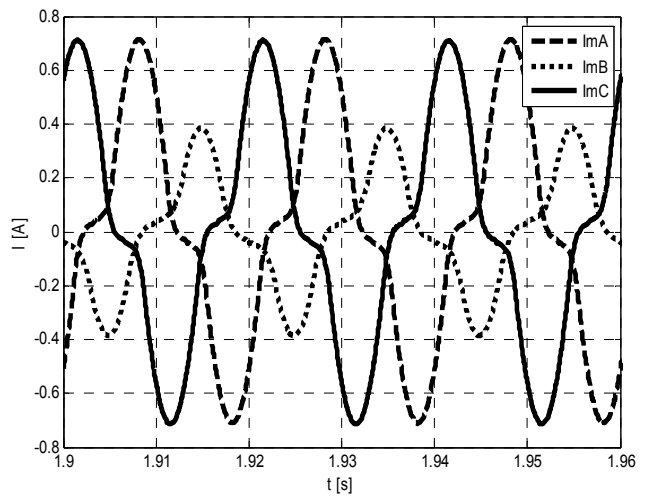

Fig. 15. Waveforms of phase currents in open-circuit delta-star connection - model.

In Fig. 16 the waveforms of open circuit currents obtained by the model are presented.

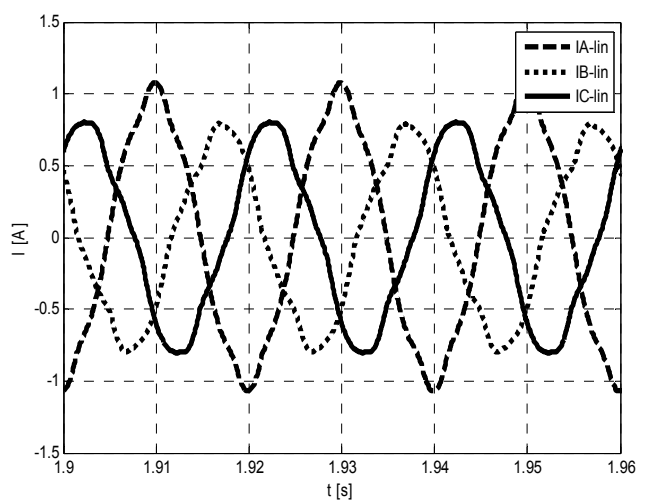

Fig. 16. Waveforms of line currents in open-circuit deltastar connection - model.
In Fig. 17 a comparison of line and magnetization currents waveforms obtained by the model is presented.

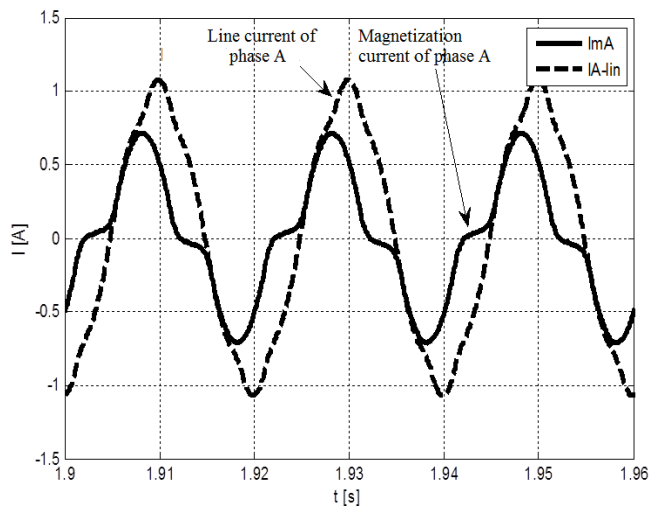

Fig. 17. Comparison of phase and line currents waveforms in open-circuit delta-star connection - model.

Harmonic analysis of line and phase currents confirms earlier conclusions. In Fig. 18 the harmonic spectra of line and phase current (Fig. 19) of phase A are presented. Similar results are obtained for other two phases.

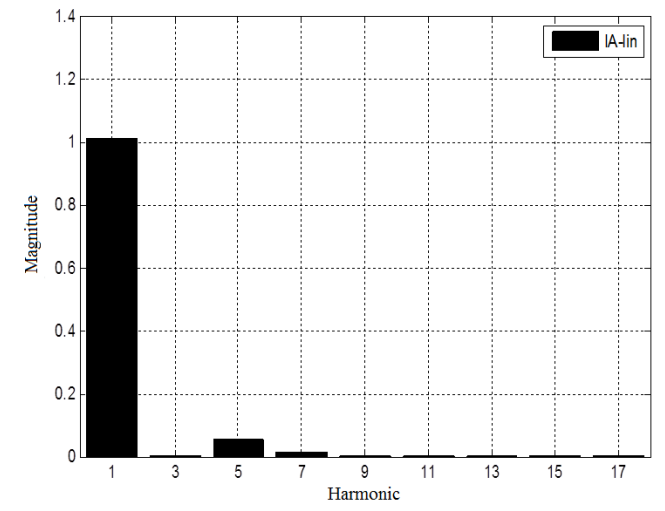

Fig. 18. Harmonic spectrum of phase A line current model.

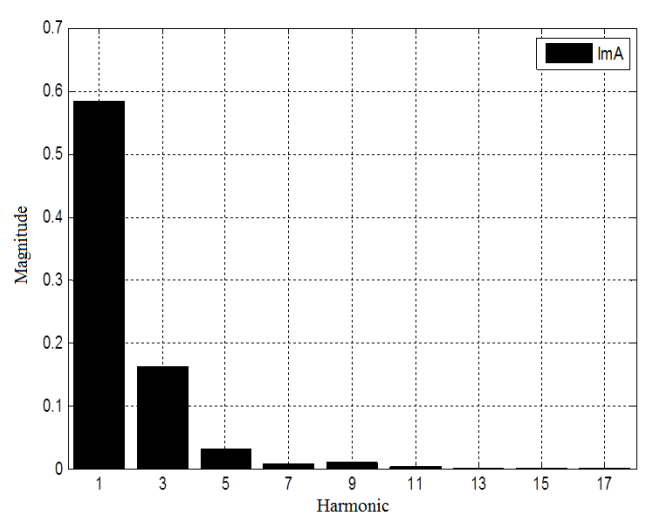

Fig. 19. Harmonic spectrum of phase A phase current model.

It is obvious that the proposed model ensures adequate results and behavior of transformer in a delta connection on the primary side because in line currents there is no third harmonic (Fig. 18) and it exists in a phase current (Fig. 19).

As an additional confirmation of the proposed model, phase shift calculations were performed. As may be seen from Fig. 20 and Fig. 21, correct results were obtained for 
two vector groups: Dyn11 and Dyn1. These vector groups, widely used in distribution systems, have a Delta on primary and a Star connection of secondary windings with a $30^{\circ}$ phase shift.

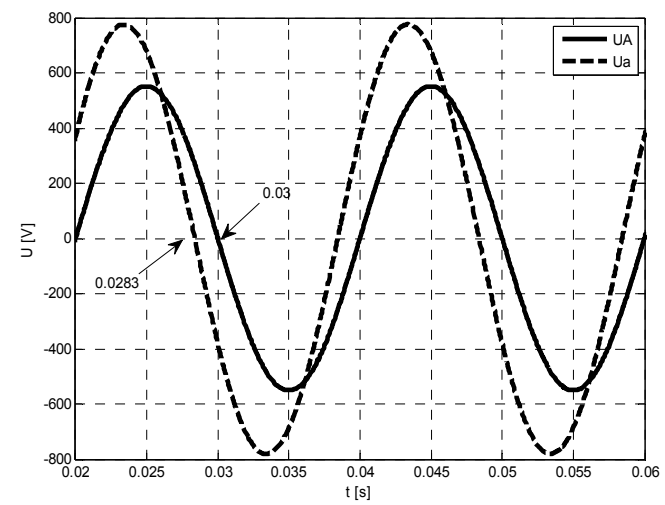

Fig. 20. Phase shift calculation for Dyn11 connection.

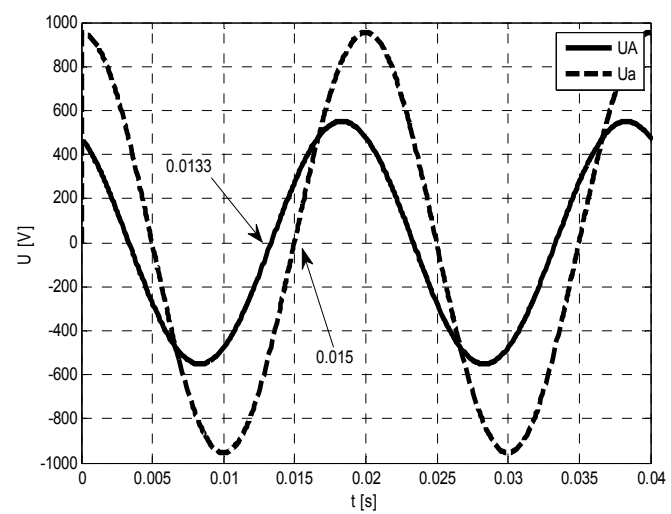

Fig. 21. Phase shift calculation for Dyn1 connection.

\section{CONCLUSION}

The proposed model of a three-phase electrical transformer is based on the fact that in a star connection with a neutral wire on the primary side, windings are connected directly to phase voltage and line (phase) currents are magnetization currents. These variables are measureable so three open-circuit characteristics can be obtained.

In the proposed model, the main contribution is that nonlinearity is included in the model in a specific way which ensures the simulation of all most common connections. The harmonic spectrum of obtained waveforms and a comparison with experiments and quotations from literature justify this approach. Nonlinearity is described by electrical variables which exclude the usage of geometrical parameters and material characteristics so transformers without documentation can easily be modeled.

More detailed verification of the proposed model will represent our future work in this very interesting field of research.

\section{REFERENCES}

[1] V. Pahwa, K. S. Sandhu, "Modelling and simulation of single-phase transformer including the main flux saturation effect", XXXII NATIONAL SYSTEMS CONFERENCE, NSC 2008, December 17 $19,2008$.
[2] A. Wilk, J. Nieznanski, I. Moson, P. Dobrowolski, G. Kostro, "Nonlinear Equivalent Circuit Model of a Traction Transformer for Winding Internal Fault Diagnostic Purposes", Proceedings of the International Conference on Electrical Machines, Paper ID 1207, 2008.

[3] Oliveira, L. M. R., Cardoso, A. J. M., "Three-Phase, Three-limb, steady-state transformer model: the case of a YnZn connection", Proceedings of the IASTED International Conference "Power and Energy Systems", pp. 467-472, Marbella, Spain, September 19-22, 2000 .

[4] W. Wiechowski, B. B. Jensen, C. L. Bak, J. Lykkegaard, "Harmonic Domain Modelling of Transformer Core Nonlinearities Using the DIgSILENT PowerFactory Software", Electrical Power Quality and Utilisation, Journal Vol. XIV, No. 1, 2008.

[5] S. Chimklai, J.R. Marti, "Simplified Three-phase Transformer Model for Electromagnetic Transient Studies", IEEE Transactions on Power Delivery. Vol. 10, No. 3, July 1995.

[6] L. Degroote, B. Renders, B. Meersman, L. Vandevelde, "Harmonic nonlinear analysis of three-phase four-wire distribution networks", 19th International Conference on Electricity Distribution, Paper 0408, Vienna, 21-24 May 2007

[7] A. Tokic, V. Madzarevic, I. Uglesic, "Numerical Calculations of Three-Phase Transformer Transients", IEEE TRANSACTIONS ON POWER DELIVERY, VOL. 20, NO. 4, OCTOBER 2005.

[8] C. A. Bulucea, D. A. Nicola, N. E. Mastorakis, D. C. Cismaru, "Modelling of Electrical Transformers in Dynamic Regimes", Proceedings of the 9th WSEAS/IASME International Conference on ELECTRIC POWER SYSTEMS, HIGH VOLTAGES, ELECTRIC MACHINES.

[9] J. A. Martinez-Velasco, B. A. Mork, "Transformer modelling for simulation of low frequency transients in power systems", 17th International Conference on Electricity Distribution, Barcelona, 1215 May 2003.

[10] A. D. Theocharis, J. Milias-Argitis, T.Zacharias, "Three-Phase Transformer Model Including Magnetic Hysteresis and Eddy Currents Effects", IEEE TRANSACTIONS ON POWER DELIVERY, VOL. 24, NO. 3, JULY 2009

[11] M. Kuczmann, Dynamic Preisach hysteresis model, Journal of Advanced Research in Physics, 2010.

[12] Dr. E. Schmidt, S. Ojak, "3D MSC/EMAS Simulation of a Three Phase Power Transformer by Means of Anisotropic Material Properties", University of Technology Vienna, Institute for Electrical Machines and Drives.

[13] G. B. Nielsen, "Dynamic modeling of a three-phase transformer", Department of Energy Technology, Electrical Energy Engineering, Aalborg University, Aalborg East, Denmark.

[14] T. Nakata, Y. Ishihara, H. Morimoto, "Analysis on Magnetic Characteristics of Three-Phase Core- Type Transformers [Part II: Non-Linear Solutions and Experimental Results for R3- Type Core ]", Memoirs of the school of engineering, Okayama University. vol. 17, October 1972.

[15] D. Dolinar, J. Pihler, B. GrEar, "Dynamic model of a three-phase power transformer", IEEE Transactions on Power Delivery, Vol. 8, No. 4, October 1993.

[16] Oliveira, L. M. R. and Cardoso, A. J. M. "Modelling and simulation of three-phase power transformers", Proceedings of the 6th International Conference on Modelling and Simulation of Electrical Machines, Converters and Systems (ELECTRIMACS 99), vol. 2/3, pp. 257-262, Lisbon, Portugal, September 14-16, 1999.

[17] M. Y. Koledintseva, J. L. Drewniak, T. P. Van Doren D. J. Pommerenke, M. Cocchini , "Mutual external inductance in stripline structures", Progress In Electromagnetics Research, PIER 80, 349-368, 2008.

[18] O. Gül, A. Kaypmaz, "The Effects of Mutual Coupling and Transformer Connection Type on Frequency Response of Unbalanced Three Phase Electrical Distribution System", Energy and Power Engineering, 238-247, 2010.

[19] G. W. Ludwig, Sayed-Amr El-Hamamsy, "Coupled Inductance and Reluctance Models of Magnetic Components", IEEE TRANSACTIONS ON POWER ELECTRONICS, VOL. 6. NO. 2. APRIL 1991.

[20] B. Mitraković, Transformatori, Naučna knjiga, Beograd, 1972.

[21] M. Simić, T. B. Šekara, S. Jokić, „Single Phase Transformer Model Based On Open Circuit Current-Voltage Characteristic " (written in Serbian), pp. 277-282, INFOTEH Jahorina 2013.

[22] M. Simić, „Model of electrical transformer based on open circuit characteristic" (written in Serbian), Master thesis, (supervisor Tomislav B. Sekara), Faculty of Electrical Engineering, East Sarajevo, September 2013. 